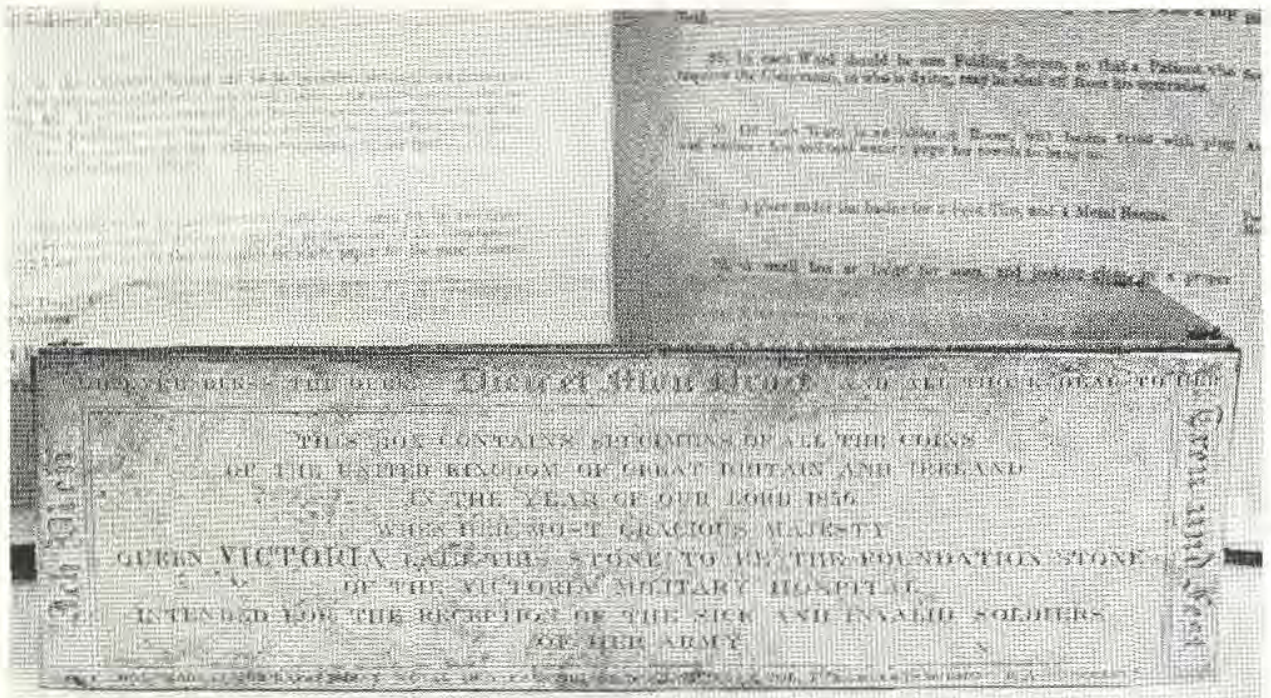

(Pholograph by courtesy of Southern Newspapers Ltd.)

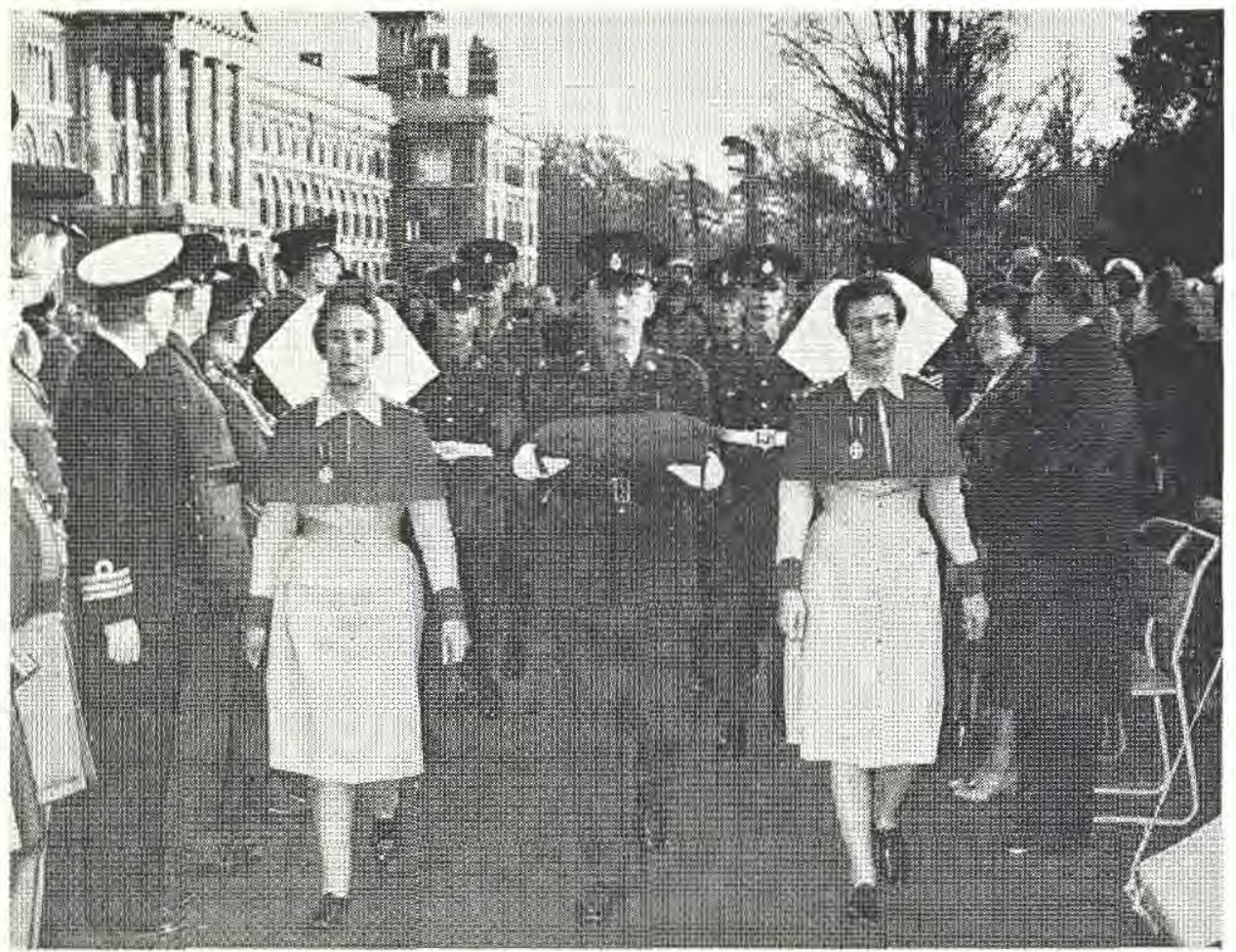

(Photograph by courtesy of Evering News and Hampshire Telegraph) 


\section{THE ROYAL VICTORIA HOSPITAL, NETLEY \\ Demolition of the old Hospital building}

THE Sword of Damocles had poised so long over the old building of the Royal Victoria Hospital, that demolition, which began in October 1966, came as quite a shock. So it was felt that the end of this grand old hospital, founded over a century ago with such pomp and splendour, should be marked by a formal ceremony.

As if by Victorian Royal favour, Wednesday, 7th December, 1966, dawned a serene and beautiful day and whilst the unit Messes entertained large groups of visitors to lunch, feverish activity by men and machines turned the muddy quagmire of the demolition area into a presentable site for the ceremony. The Band of the Royal Army Medical Corps was playing to the large crowd in the bright December sunshine, as the V.I.Ps took their places by the foundation stone. An interesting figure among the distinguished gathering of guests, which included eight Generals and an Admiral, was Mr. H. F. Longmoor, son of Surgeon General Sir Thomas Longmoor, who was the Professor of Military Surgery at the Army Medical School for oyer thirty years and recorded as the third Commandant of the Royal Victoria Hospital.

Major General W. B. F. Brennan, C.B., Q.H.P., D.D.M.S., Southern Command, representing the Director General Army Medical Services, first welcomed the visitors. He recalled how the old hospital had been the inspiration over the past century to generations of Army doctors and nurses in their care of the hundreds of thousands of sick and wounded soldiers at Netley.

Flanked by two Chelsea Pensioners in their scarlet uniforms, the Commanding Officer gave the signal for the lifting of the foundation stone. A powerful bulldozer, painted a bright primrose for the occasion, pulled up inch by inch the huge block of Welshg ranite. The beginning of the end! It was a moment when men who have shared the past, experience their own deep emotions and private thoughts and many were there who had long and intimate memories of the old place. But then, in a matter of minutes, although it seemed much longer, Mr. Bill Perry, in an immaculate white demolition helmet, was down under the stone. He was seen to lever up a small rectangular block from a cavity in the lower stone. He then triumphantly emerged carrying a wet, dirty, dark green box and placed it on a table. There were screws at each corner of the box and as none yielded an iota to the screwdriver powered by the Commanding Officer, the tension mounted. Near panic was converted into brute force and with a prizing motion the lid opened. In quick succession appeared a small round wooden box, a silver Crimea medal with four clasps, a Victoria Cross and finally a soggy bundle of green stained documents. The Cross and Medal were held up elatedly for all to see and for the scores of camera men and reporters.

The metal box and its contents were then presented to the Representative Colonel Commandant, Major General A. Sachs, C.B., C.B.E., M.Sc., M.D., F.C.Path., F.R.C.P., who said that they would be preserved as a tribute to the memory of all those, staff and patients, who had lived and died within the walls of this grand old hospital. He hoped that these treasures would also be an inspiration to the young men and women in the Medical Services of today. General Sachs then placed the box on a scarlet cushion held by Regimental Sergeant Major J. McCran, R.A.M.C., who was waiting with an escort party formed by two Q.A.R.A.N.C. Officers in their bright scarlet and grey, two smart young apprentices from the R.A.M.C. Depot and two NCOs of the hospital staff. To the strains of "Washington Post" and "Bonny Nell", the bearer party led by the R.A.M.C. 
Band, marched down the long, battered, frontage of the old building, under the pine woods and into the hospital Social centre.

Here was displayed an impressive collection of historic mementos relating to the history of the Royal Victoria Hospital.Pride of place was given to the afternoon's discoveries and guarding them were two young apprentices, looking very smart in the uniform of medical orderlies in Victorian times.

The Victoria Cross, the Crimea Medal and the coins are now in the safe keeping of the Commandant of the Royal Army Medical College, Millbank and it is proposed to display them either in the R.A.M.C. Historical Museum or in the R.A.M.C. Headquarter Mess. There are sixteen coins in the Netley collection, which include two gold, ten silver and four copper pieces. All are in excellent condition with the exception of the copper coins, which are extensively oxidised. The waterlogged documents were taken immediately after the ceremony to the Civil Record Office of Southampton Corporation and the Corps is much indebted to Mr. G. A. Wilson for an expert feat of restoration.

According to the recovered documents which include the plans of the hospital, there should have been a parchment, describing the ceremony of the laying of the foundation stone and bearing the signatures of the Queen, the Prince Consort and the Secretary of State. This document has not been found. Did it disintegrate through dampness in the box or did, perhaps, some official fail to put it there? So the affair of the Netley foundation stone ends as it began - with a mystery!

J.F.D.M.

\section{Medical Photography}

An exhibition by the Medical Group of the Royal Photograhic Society is to be held in the Claire Wand Gallery, British Medical Association Tavistock Square London W.C.1 from 3rd March to 27 th April, 1967-Monday to Friday 9 a.m. to $5-30$ p.m. Saturday 9 a.m. to 12 noon.

\section{Pegasus Trophy Competition 1966}

Held on Salisbury Plain 15/16th October, 1966 and consisted of a 30 mile cross country march and a map reading exercise. Teams were marked on time, equipment discipline and a medical (casualty collecting) task.

Fourteen teams from Medical units in all home commands competed Results were:1 st, 10 (London) General Hospital R.A.M.C.(T.A.)

2nd, 'B' team 133 (H.C.) Field Ambulance R.A.M.C.(T.A.)

3rd, 47 (H.C.) Field Ambulance R.A.M.C.(T.A.) 